\title{
FUEL ALCOHOL PLANT LOCATION IN THE PHILIPPINES
}

\author{
Louie A. Divinagracia and Michael W. Babcock*
}

Location theory contains two principal models. One of these emphasizes spatial cost variation, holding demand factors constant. This is the least cost approach pioneered by Alfred Weber. The other model emphasizes market demand factors assuming costs to be spatially invariant. This is the familiar central place theory traceable to Losch and Christaller. These two partial models continue to be dominant themes of location theory despite several notable attempts to formulate a general model (Isard and Greenhut).

Perhaps this is because the advantages of partial models exceed the disadvantages. The main disadvantage is the "holding constant" of variables that may be important to the subject of the investigation. The principal advantage is the ability to draw clear conclusions based on analysis of a small number of important explanatory variables. General models incorporate more variables and emphasize the interdependence of the economic system. However conclusions are difficult to obtain when several explanatory variables have conflicting impacts on the dependent variable.

Most empirical studies of manufacturing location have employed the least cost framework, for example Babcock, Kennelly, Taylor, Isard and Capron, and Lindberg. These studies have been criticized for failure to incorporate the impact of distance on demand, locational interdependence, and agglomeration economies. These are significant criticisms of studies which atempt to describe the location patterns of entire industries. However they are somewhat less important for individual plant location studies. This is because the location of other activities can reasonably be assumed to be fixed.

The objective of this paper is to present a case

\footnotetext{
*University of Philippines-Los Baños, and Kansas State University, Manhattan, respectively.
}

study of applied location economics-the optimal location of fuel alcohol plants in the Philippines.

In February 1980 the Philippine government established PNAC (Philippine National Alcohol Commission) to administer the Philippine Alcogas Plan. The principal objective of the Plan is to reduce dependency on oil imports and achieve a more favorable balance of trade. To achieve this, a 10 percent mixture of fuel aicohol (increasing to 17 percent by 1985) is blended with gasoline. The fuel alcohol is produced from domestic agricultural raw materials, primarily sugarcane. Based on a forecast of demand for gasoline, the Philippine government has determined a need for fourteen new distilleries. The study will determine the optimal plant location for one distillery with respect to a given point market and raw materials area. The methodology and conclusions are applicable to the other plants as well.

\section{The Model}

The market for the fuel alcohol is the oil refinery city of Rosario, located approximately halfway between Manila and the sugarcane producing area to the south (see Figure 1). Since sugarcane is the primary input, the possible plant locations include a number of cities in the sugarcane producing area (including three sites suggested by PNAC), the market, and other intermediate points.

A transportation cost minimizing approach is employed to determine the optimal location. This is because the circumstances of this particular case closely correspond to the assumptions of the transport cost minimization model. ${ }^{1}$ The primary assumptions of the model are:

1. The quantity demanded at the market is fixed and known.

2. The market is a point as opposed to a spatial market. 


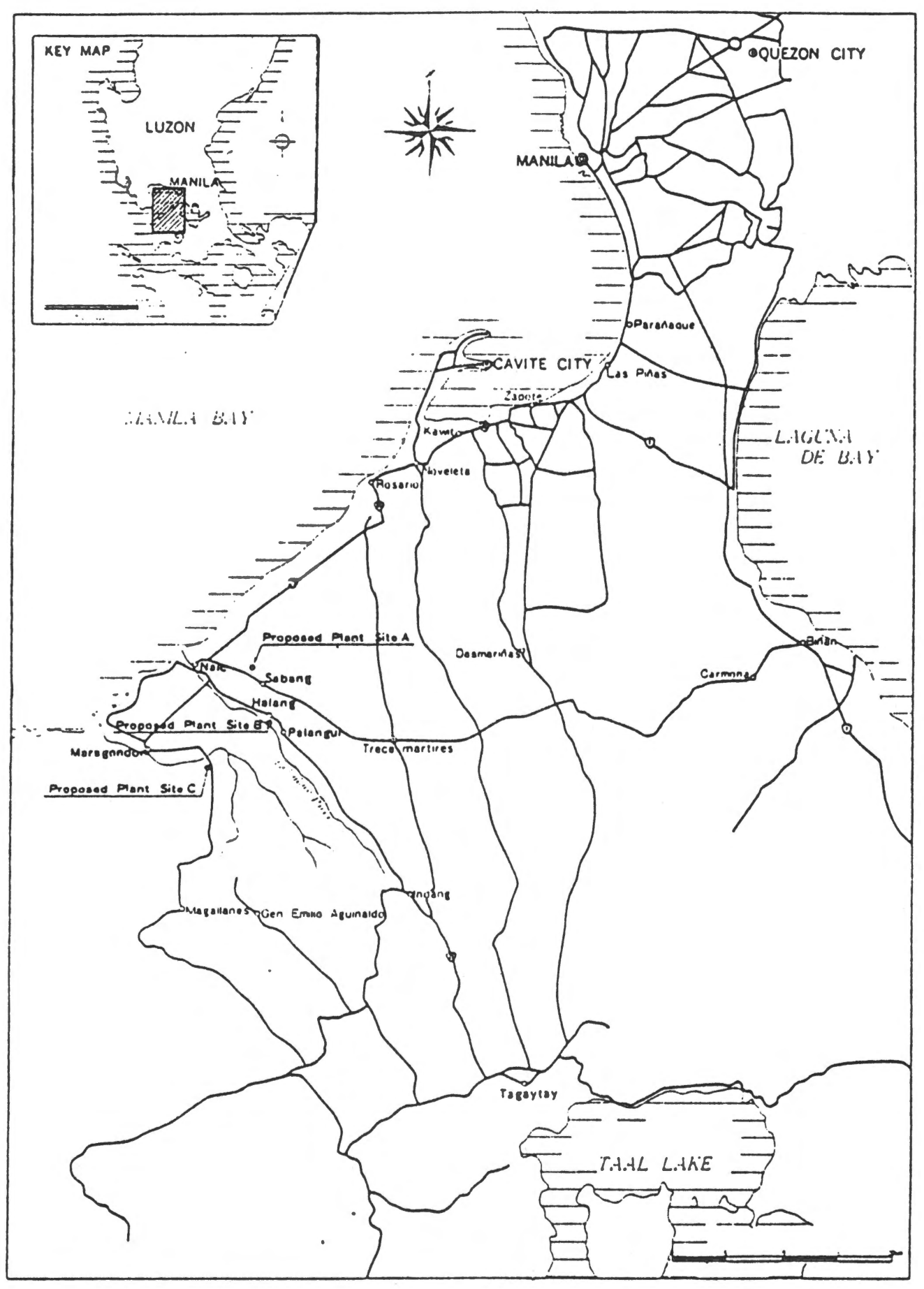

Figure 1. Location Map

46 
3. No spatial variation in the price of nontransferable inputs.

4. The production function is a fixed coefficients production function.

In the problem at hand the quantity demanded is the given annual output of the plant and is based on a forecast of gasoline demand and proposed blending proportions of gasoline and fuel alcohol. The market is the oil refineries at Rosario rather than a spatial market. The main non-transferable inputs are energy and labor. Neither of these account for a significant proportion of production costs and there is little spatial variation in the prices of these inputs (see Table 1).

The existing technology requires a fixed amount of sugarcane input per unit of fuel alcohol. Finally there is a single point market and a single transferable input (sugarcane). Thus the circumstances of the case are nearly identical to what is commonly referred to as the "straight line location problem."

The least cost location can be determined by initially measuring the locational pulls of the market and raw material area. This can be accomplished by computing the ideal weights of the market and sugarcane area. ${ }^{2}$ Let $\mathrm{W}_{\mathrm{s}}$ be the number of tons of sugarcane required per ton of fuel alcohol. Also let $t_{s}$ be the transport rate per ton-kilometer of sugarcane and $t_{a}$ the transport rate per ton-kilometer of fuel alcohol. The ideal weights are defined as follows.

$\mathrm{S}$ - Ideal weight (sugarcane area) $\quad \mathrm{W}_{\mathrm{s}} \times \mathrm{t}_{\mathrm{s}}$ M - Ideal weight (market) $\quad 1 \times t_{a}$

Thus if $\mathrm{S}>\mathrm{M}$ the locational pull of the sugarcane production area would exceed that of the market and the optimal location would be at a raw materials site. Conversely, if $\mathrm{M}>\mathrm{S}$ the firm would minimize transport costs at the market.

\section{TABLE 1}

Fuel Alcohol Cost Components at Optimal Location Percent of Total

\begin{tabular}{lc} 
Cost Item & Costs \\
\hline Raw Material Acquisition & 85 \\
Raw Material Transport & 7 \\
Energy & 2 \\
Labor & 5 \\
Final Product Transport & 1 \\
\hline
\end{tabular}

If $\mathrm{M}>\mathrm{S}$ no further analysis is needed. However if $\mathrm{S}>\mathrm{M}$, the least cost site within the sugarcane production area must be determined. Based on the forecast demand for fuel alcohol and sugarcane production capacity in the area, the distillery must obtain sugercane from seven supply points. If $S>M$, each of the seven supply points, along with other sites suggested by PNAC, must be evaluated as possible distillery locations.

Evaluation of distillery locations in the raw material area involves measurement of two major transport cost components. These are the costs of assembling the necessary raw material at the plant location and the cost of shipping fuel alcohol to the market. Let the former be designated procurement cost and the latter distribution cost.

Total procurement $\operatorname{cost}\left(\mathrm{P}_{\mathrm{i}}\right)$ for a given plant site $\mathrm{i}$ is:

$$
\begin{aligned}
& \text { (1) }-P_{i}=\sum_{j=1}^{n}\left(q_{j}\right)\left(t_{s}\right)\left(k_{i j}\right) \\
& \text { i - plant site } \quad \mathrm{i}=1 \ldots \mathrm{n} \\
& \text { j - raw material source } \\
& \mathrm{j}=1 \ldots \mathrm{n}
\end{aligned}
$$

Total distribution $\operatorname{cost}\left(\mathrm{D}_{\mathrm{i}}\right)$ for a given plant site $i$ is:

(2) $\mathrm{D}_{\mathrm{i}}=\left(\mathrm{q}_{\mathrm{i}}\right)\left(\mathrm{t}_{\mathrm{a}}\right)\left(\mathrm{k}_{\mathrm{id}}\right)$

$q_{i}$ - tons of fuel alcohol transported from plant site i

$t_{a}$ - transport cost per ton-kilometer of fuel alcohol

$k_{\text {id }}$ - distance from plant site $\mathrm{i}$ to demand point d

Thus the total transport cost $\left(\mathrm{T}_{\mathrm{i}}\right)$ of any given plant site $i$ is:

$$
\text { (3) } T_{i}=P_{i}+D_{i}
$$

\section{The Least Cost Location}

Fuel alcohol is a weight losing production process requiring substantial bulk reduction of sugarcane. Thus the ideal weight of the raw material area is substantially greater than that of the market. Thirteen tons of sugarcane are 
TABLE 2

Annual Sugarcane Requirements of Fuel Alcohol Distillery

\begin{tabular}{lcc}
\hline Raw Material Source & $\begin{array}{c}\text { Sugarcane } \\
\text { Requirements }\end{array}$ & $\begin{array}{c}\text { Percent } \\
\text { Of Total }\end{array}$ \\
\hline Trece Martires City & 39,624 tons & 25 \\
Naic & 2,496 & 2 \\
Indang & 2,080 & 1 \\
Magallanes & 15,600 & 10 \\
Maragondon & 43,680 & 28 \\
GE Aguinaldo & 2,600 & 2 \\
Palangui & 52,000 & 32 \\
$\quad$ TOTAL & 158,080 & 100 \\
\hline
\end{tabular}

Source: Philippine National Alcohol Commission

required to make one ton of fuel alcohol. The transportation rates per ton-mile of input and output are .8 pesos and 1.27 pesos respectively. ${ }^{3}$ Thus the ideal weights of the raw materials area and market are:

$$
\begin{aligned}
& \mathrm{S}=13.0 \times .8=10.4 \\
& \mathrm{M}=1 \times 1.27=1.27
\end{aligned}
$$

The least cost site within the raw material area can be determined by the procurement cost-distribution cost model. The quantities of sugarcane transported from each raw material site $\left(\mathrm{q}_{\mathrm{j}} \mathrm{s}\right)$ were provided by PNAC. The data are based on a number of considerations. These include historical production in the area, expected demand for fuel alcohol, and input requirements for fuel alcohol production.
Agronomy studies were also conducted to determine potential sugarcane output in areas not currently planted in cane. The data are in Table 2.

The quantity of fuel alcohol demanded $\left(q_{i}\right)$ was also provided by PNAC. The demand is based on expected demand for gasoline and planned blending proportions of gasoline and fuel alcohol. The quantity demanded is 12,168 tons per year.

The minimum highway distances from raw material sites $\left(k_{i j}\right)$ and the market $\left(k_{i d}\right)$ for each alternative plant site were provided by PNAC. They are in Table 3. The transport rates of input $\left(t_{s}\right)$ and output $\left(t_{a}\right)$ are the same as those mentioned above.

The procurement costs for each potential plant site are in Table 4. Each number in the table repreents the cost of transporting input from a given raw material source to the plant site. The transport costs in Table 4 are based on the quantities of sugarcane transported from each source (Table 2), the distances from sources to plant sites (Table 3 ) and the assumed transport rate of sugarcane.

The distribution costs shown in Table 5 are based on the required annual output of the plant (12,168 tons), the distances from plant sites to Rosario (Table 3), and the assumed transport rate of fuel alcohol.

The total transport costs for each raw material site and candidate sites $\mathrm{A}, \mathrm{B}$, and $\mathrm{C}$ are in Table 5. An examination of Table 5 reveals that

TABLE 3

Distances From Potential Distillery Sites

\begin{tabular}{|c|c|c|c|c|c|c|c|c|}
\hline \multirow[b]{2}{*}{ Candidate Sites } & \multicolumn{7}{|c|}{ Raw Material Sources } & \multirow{2}{*}{$\begin{array}{c}\begin{array}{r}\text { Demand } \\
\text { Point }\end{array} \\
\text { Oil } \\
\text { Depot }\end{array}$} \\
\hline & Marangondon & Naic & Indang & Magallanes & Palangui & $\begin{array}{l}\text { GE } \\
\text { Aguinaldo }\end{array}$ & T. Martires & \\
\hline Maragondon & - & 10.8 & 36.9 & 21.3 & 18.0 & 19.2 & 30.6 & 35.1 \\
\hline Naic & 10.8 & - & 28.8 & 32.1 & 9.9 & 30.0 & 19.8 & 24.3 \\
\hline Indang & 36.9 & 28.8 & - & 55.4 & 18.9 & 31.2 & 20.1 & 45.6 \\
\hline Magallanes & 21.3 & 32.1 & 55.4 & - & 39.3 & 7.8 & 53.4 & 56.4 \\
\hline Palangui & 18.0 & 9.9 & 18.9 & 39.3 & - & 47.1 & 30.8 & 34.2 \\
\hline GE Aguinaldo & 19.2 & 30.0 & 31.2 & 7.8 & 47.1 & - & 51.3 & 54.3 \\
\hline T. Martires & 30.6 & 19.8 & 20.1 & 53.4 & 30.8 & 51.3 & - & 25.5 \\
\hline A & 17.1 & 6.3 & 35.1 & 38.4 & 16.2 & 36.3 & 15.3 & 30.6 \\
\hline B & 15.0 & 8.4 & 21.9 & 36.3 & 3.0 & 34.2 & 28.2 & 32.7 \\
\hline C & 7.2 & 18.0 & 44.1 & 14.1 & 25.2 & 12.0 & 37.8 & 42.3 \\
\hline
\end{tabular}

UNIT: KILOMETERS

Source: Philippine National Alcohol Commission 
TABLE 4

Procurement Costs of Potential Distillery Sites

Unit: Thousand Pesos

Raw Material Sources

\begin{tabular}{lccccccc}
\cline { 2 - 7 } Candidate Sites & Maragondon & Naic & Indang & Magallanes & Palangui & Aguinaldo & T. Martires \\
\hline Maragondon & - & 21.568 & 61.402 & 265.824 & 748.800 & 39.936 & 969.989 \\
Naic & 377.395 & - & 47.924 & 400.608 & 411.840 & 62.400 & 627.640 \\
Indang & 1289.434 & 57.513 & - & 691.392 & 786.240 & 64.896 & 637.150 \\
Magallanes & 744.307 & 64.104 & 92.185 & - & 1634.880 & 16.224 & 1692.727 \\
Palangui & 628.993 & 19.770 & 31.450 & 490.464 & - & 97.968 & 976.329 \\
GE Aguinaldo & 670.924 & 59.910 & 51.917 & 97.344 & 1959.360 & - & 1626.159 \\
T. Martires & 1069.286 & 39.541 & 33.446 & 666.432 & 1281.280 & 106.704 & - \\
$\quad$ A & 597.542 & 12.581 & 58.406 & 479.232 & 673.920 & 75.504 & 484.995 \\
$\quad$ B & 524.160 & 16.775 & 36.442 & 453.024 & 24.800 & 71.136 & 893.912 \\
C & 251.597 & 35.946 & 73.382 & 175.968 & 1048.320 & 24.960 & 1198.222 \\
\hline
\end{tabular}

Naic is the least cost site. Both the distribution and procurement cost components are lower than any other site. The closest alternative, site $B$, is about 10 percent more costly than Naic.

\section{Conclusion}

This paper demonstrates the utility of least cost location theory when the circumstances of an actual case closely correspond to the assumptions of the model. A least cost transportation model is employed to determine the optimal plant location. Conventional methods of locational analysis are employed including ideal weights, procurement cost, and distribu-

\section{TABLE 5}

Procurement, Distribution, and Total Transport Costs Potential Distillery Sites

Unit: Thousand Pesos

\begin{tabular}{lccc}
\hline & & & Procurement \\
Candidate Sites & Cost & Cost & $\begin{array}{c}\text { Total } \\
\text { Cost }\end{array}$ \\
\hline Maragondon & 2107.519 & 541.102 & 2648.621 \\
Naic & 1927.807 & 374.609 & 2302.416 \\
Indang & 3526.625 & 702.970 & 4229.595 \\
Magalannes & 4244.427 & 869.462 & 5113.889 \\
Palangui & 2244.974 & 527.227 & 2772.201 \\
GE Aguinaldo & 4465.614 & 837.086 & 5302.700 \\
T. Martires & 3196.689 & 393.107 & 3589.796 \\
$\quad$ A & 2382.180 & 471.730 & 2853.910 \\
$\quad$ B & 2020.249 & 504.103 & 2524.352 \\
$\quad$ C & 2808.395 & 652.097 & 3460.492 \\
\hline
\end{tabular}

tion cost. The conclusion of the analysis is consistent with theoretical expectations. Weight losing production processes locate close to raw materials sites.

Government subsidy of unconventional energy sources is controversial. In the late 1970 s when petroleum prices were rising rapidly, many petroleum importing countries began subsidizing a variety of unconventional energy alternatives. Now that petroleum prices have leveled off these projects appear to be much less attractive.

Different countries have responded to the current situation in alternative ways. Much of the U.S. synfuels program has been indefinitely postponed. However the Philippine government has decided to continue most of its programs. Either strategy entails risk depending on the rate of future petroleum price increase. If petroleum price increases continue to abate and no oil embargoes occur, the current U.S. policy seems rational. However the opposite scenario would reward Philippine strategy.

\section{FOOTNOTES}

${ }^{1}$ For a full discussion of the assumptions and analysis of the straight line location problem see Nourse (10, pp. 7479).

${ }^{2}$ For more complete discussion of the ideal weight concept see Smith (11, pp. 238-239).

${ }^{3}$ The transport rates provided by PNAC are truck rates. The rates were obtained from trucking cost studies. Since most trucking costs are variable, truck rates closely correspond to trucking costs. Thus the assumption of rates equal to costs is a reasonable one. 


\section{REFERENCES}

Babcock, M. W. "An Empirical Locational Analysis of the Wheat Flour Milling Industry," Review of Regional Studies, Vol. 6, Winter, 1976, pp. 11-18.

Christaller, W. Die Zentralen Orte in Suddeutschland (1933). Translated by Baskin, C. W. as Central Places in Southern Germany, Prentice-Hall: Englewood Cliffs, New Jersey, 1966.

Greenhut, M. L. Plant Location in Theory and Practice, University of North Carolina Press: Chapel Hill, 1956.

Isard, W. Location and Space Economy, MIT Press: Cambridge, Mass., 1956.

Isard, W. and Capron, W. H. "The Future Locational Pattern of Iron and Steel Production in the United States," Journal of Political Economy, Vol. 57, 1949, pp. 118-133.

Kennelly, R. A. "The Location of the Mexican Steel Industry," Revista Geografica, Vol 15, pp. 109-129; Vol. 16, pp.
199-213; Vol. 17, pp. 60-77, 1954-55.

Lindberg, O. "An Economic-Geographical Study of the Localization of the Swedish Paper Industry," Geografiska Annaler, Vol. 35, 1953, pp. 28-40.

Lösch, A. The Economics of Location, Yale University Press: New Haven, 1954.

Nourse, H. O. Regional Economics, McGraw-Hill: New York, 1968.

Smith, D. M. Industrial Location, John Wiley \& Sons: New York, 1981.

Taylor, J. Problems of Minimum Cost Location: The Kuhn and Kuenne Algorithm, Occasional Paper No. 4, Department of Geography, Queen Mary College, University of London, 1975.

Weber, A. Theory of the Location of Industries, translated by Friedrich, C. J., University of Chicago Press: Chicago, 1929. 